\title{
The Inter-organizational Business Case in ES Implementations: Exploring the Impact of Coordination Structures and Their Properties
}

\author{
Silja Eckartz ${ }^{1}$, Christiaan Katsma², Maya Daneva ${ }^{1}$ \\ ${ }^{1}$ Information Systems Group, ${ }^{2}$ Information Systems and Change Management \\ University Twente, Enschede, The Netherlands \\ \{S.M.Eckartz, C.P.Katsma, M.Daneva\}@Utwente.nl
}

\begin{abstract}
Developing the business case (BC) for an inter-organizational network is a major challenge. Factors like competition and differences in semantics between actors influence the stakeholders' willingness to share information necessary for the BC development. In this paper we develop an exploratory framework showing the effect that coordination structure and project scope have on the development of a shared BC. We defined several coordination properties, such as competition, decision making location and decision power that mitigate this effect. We applied the framework in a case study where a BC is developed for an inter-organizational network. Our findings show that current $\mathrm{BC}$ development methods need to be re-stated and complemented by extra tools and interventions to support stakeholders in the inter-organizational specific setting.
\end{abstract}

Keywords: Inter-organizational coordination, Business Case, Information sharing, Decision making

\section{Introduction}

Enterprise systems (ES) can be defined as commercial software packages that enable the seamless integration of information and information-based processes within and across functional areas in an organization [1]. Today ES do not only enable the integration and coordination of transaction-oriented data and business processes within one organization, but also go one step further and support the connection and management of information flows across several organizations. Such interorganizational coordination is necessary in interactions between profit-and-loss responsible business units, or between independent companies, connected by IT that work together to jointly accomplish a task for a specific period of time [2].

This crossing of organizational boundaries not only increases the complexity of the ES but also creates substantial differences in semantics, processes, information and goals between the different actors [3]. Thus, the multiple actors that collaboratively work in inter-organizational coordination to reach a common goal often encounter problems when they need to share information in order to make a joint decision. In 
our research, we focus specifically on the process of how multiple actors arrive at a joint decision about whether or not to invest in an ES. Therefore, we will analyze the process of shared business case development (BCD).

The purpose of developing a business case $(\mathrm{BC})$ is to describe the main rationale behind the ES implementation process. A BC enables participants to estimate the expected costs and benefits of an ES for the adopting organization [4-6]. In the field of Information Systems (IS) research, scholars take different perspectives upon this relatively young research sub-field [7-8]. Kishore et al. [9] take an IS design perspective and include coordination theory to exemplify the extra complexity due to the involved actors. Our research logically continues the line of reasoning of the prior contributions and uses this knowledge to apply it in the BC context. In this paper, we focus on the impact of the project scope and coordination structure among the involved actors during the early stages of inter-organizational ES implementations, when the $\mathrm{BC}$ is initiated.

Typical coordination properties, such as, decision power, competition and decision making location depend on the project scope and coordination structure among the organizations and are expected to influence the $\mathrm{BC}$. These project realities require an adapted BCD approach that pays attention to the specific situation of the interorganizational setting. In this paper we derive an exploratory framework that contains the identifying coordination properties for the BC during such ES implementations.

Based on this line of reasoning, we set out to answer the following research question: What are the effects of project scope and coordination structure during the development of an inter-organizational business case?

\section{Research Method}

This paper presents results that are part of a running research project on the implementation of inter-organizational IS and ES in particular. We build upon a rich inventory of ES implementation experiences and case study research. This paper investigates the deployment of BCD during the implementation process and focuses on the increased complexity due to inter-organizational coordination structure. Fig.1 shows our research model. It indicates the sections of the paper that discuss the key elements of the research model.

\begin{tabular}{|c|c|c|c|c|}
\hline $\begin{array}{l}\text { Project Context } \\
(\S 3.2 \text { and } \S 3.3)\end{array}$ & $\rightarrow$ & Coordination $(\$ 3.4)$ & $\rightarrow$ & $\begin{array}{c}\text { Shared BCD } \\
(\$ 3.1)\end{array}$ \\
\hline
\end{tabular}

Fig. 1. Research model

We deployed the following research approach that also gives a short overview of the sections in our paper:

We first conducted an extensive literature review [10] covering scientific publications in the areas of BCD [6, 11], coordination mechanisms [9, 12-13], and inter-organizational ES implementation. Based upon this review we conclude relevant findings on the deployment of the BC during ES implementations in $\$ 3.1$. In sections $\$ 3.2-3.4$, we evaluate these findings from the perspective of the coordination 
structures in inter-organizational collaborations in particular and derive our exploratory framework. The objective of our framework is to make the increased complexity of the inter-organizational BCD during the early stages of the interorganizational ES implementation process explicit. We explain the deployment of our framework in a case study in $\$ 4$. The source of our empirical material is a large business network in the transportation sector in the Netherlands. It is formed by barge and terminal operators in the Rotterdam Harbor. Two researchers, within a period of 6 months, deployed participative observation techniques in workshops, conducted interviews, observed negotiation between actors, and, in a few occasions, guided the attempt to develop a shared BC for the network. We used a diary approach to record incidents. We reflected on the relevant events with different interviewees in informal unstructured interviews. In hindsight we participated in the following sessions:

- 6 individual interview meetings with different actors to get an understanding of the situation at hand and of the important concerns of each actor. These meetings concern unstructured interviews using mostly qualitative data.

- 5 meetings with different stakeholders (several barge operators the Transportation ministry, and the official from the Harbor of Rotterdam).

- 3 collaborative workshops with most stakeholders present except for the terminal operators.

We coded and clustered the information that was collected by means of our interviews and the other empirical materials using our conceptual framework in section $§ 3.4$.

\section{Development of an Exploratory Framework}

This section elaborates on our research model (Fig. 1 from $§ 2)$.

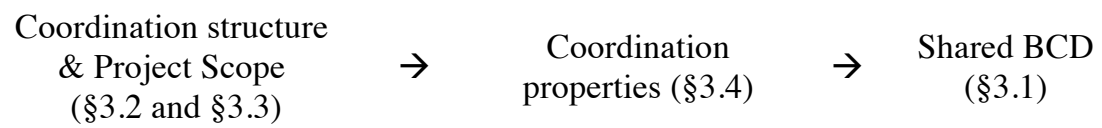

First, we specify the issues of shared BCD $(\$ 3.1)$, then we proceed from the left, and specify coordination structure and project scope as the two main identifying determinants ( $\$ 3.2$ and $\S 3.3$ ). We continue our line of reasoning by further zooming in on these two identifying determinants and specify what we call coordination properties, and then, we complete our exploratory framework in $\S 3.4$.

\subsection{Introduction to Shared BCD}

Our literature review and empirical studies indicate a variety in terminology and ambiguity in used terms. While this in itself is not unique for the IS field, for clarification purposes and to position our line of reasoning we start with a definition of what we mean by the concept of "Business Case". A BC as an artifact (a document possibly accompanied by designs or models) that specifies the main rationale and expected value for the ES-adopting organization. The BC evaluates and presents 
different implementation options, based on the expected costs, benefits and risks of each option during the entire implementation process. It is the result from a BCD process that is deployed between consultants and stakeholders from the ES-adopting organization. A BC however, should contain more than just a financial analysis of an action to take. The (non-)financial benefits, alignment, costs and risks, should be complemented with information on the methods and rationale that were used to quantify the benefits and costs [14]. The BCD is an iterative, tool-supported process that relies on stakeholders from different parts of the organization with different business knowledge.

An important aspect of BCD in inter-organizational settings is its linkage to the model that describes how the business network creates value for its clients and how the network distributes the value among the partner companies. This model, also called value model [15], serves two different, but related purposes: (i) it helps each partner company do a profitability assessment for themselves based on the information provided in the partner company's individual BC, and (ii) it helps assess if the entire network of cooperating organizations is profitable. If the network partners want to e.g. implement a shared ES, which is used by all partners, they need to make a shared investment decision, based on a joint $\mathrm{BC}$ for the entire network.

As the introduction indicated, BCs often cross boundaries, e.g. organizational, functional, and budgetary. Thus, for a network to build a BC, diverse input from all involved entities is required which add up to complex BCD [14]. This is because despite partners' awareness of the need to share information, they might lack a shared understanding of the terminology used, might hesitate to release sensitive information (e.g cost data) due to competition or might disagree on how costs and benefits are distributed in a network.

\subsection{Coordination Structures}

Inter-organizational relations can be classified based on the type of relationship between partners and their coordination structure. A distinction can be made between markets and non-markets [16]. Markets are characterized by discrete interactions and limited personal involvement [17], while non-market interactions are usually based on some form of relationship between the partners. The latter can be classified as being either hierarchical or of a network nature. Hierarchical partnership structures, e.g. franchise or outsourcing contracts, rest on unilateral interaction and an authority relationship. Inter-organizational relations organized in a market structure, have often a short term focus and are mainly based on the price mechanisms. They fall into centralized and decentralized market structures. The first involve an intermediary or broker, and are characterized by high competitiveness and opportunistic behavior [18]. The network as a coordination structure is characterized by cooperation, collaboration, and the sharing of information [19]. Thus, it is different from a pure market structure; in fact, it is a hybrid of hierarchy and market based on bilateral, often long term interaction between partners. Partners are "free" to choose their counterparts (as in a market structure) and members are operationally dependant on each other (comparable with a hierarchy [20]). Such networks between partners are often referred to as collaborations. 


\subsection{Project Scope}

To define the project scope, we make a distinction between single and multiple actors. For the purpose of this paper, an actor is defined as a decision making entity. When referring to a single actor, we mean in most cases one organization that may consist of several individuals but they do not have separate decision making power. Because we analyze the context of inter-organizational coordination, for the rest of the paper we will focus on the case of multiple actors only. If the project involves multiple actors, the majority of actors can either be in the same business sector, e.g. a payment system supporting a network of banks (Fig.2, column a) or in different business sectors, e.g. a typical retail supply chain integration network (column b). Moreover, the interorganizational network can consist of actors from both the same as well as different sectors (column c). The project complexity increases from column (a) to (c).

\begin{tabular}{|l|l|l|l|l|l|}
\hline \multicolumn{9}{|c|}{ Project Scope } \\
\hline $\begin{array}{l}\text { a) Multiple actors } \\
\text { same sector }\end{array}$ & $\begin{array}{l}\text { b) Multiple actors, } \\
\text { different sectors }\end{array}$ & $\begin{array}{l}\text { c) Multiple actors from both } \\
\text { the same and different sectors }\end{array}$ \\
\hline & Sector & 1 \\
& 1
\end{tabular}

Fig. 2. Influence of project scope

\subsection{Conceptual Framework \& Coordination Properties}

There is relevant research into the detailed properties and influences of coordination structure [3, 20-21]. Based on these sources, we find that coordination structure and project scope are expected to influence the following six coordination properties:

- Decision-making location (coordination authority/ level of control),

- Competition (resource sharing structure, risk/ reward sharing) [22]

- Decision Power [23]

- Semantics (use of similar language and sharing of similar mental models)

- Information sharing,

- Goals and objectives [3].

Fig. 3 shows our exploratory framework including the relationships between the different determinants and exemplary values (depicted in the boxed elements). We will explain how the coordination properties influence the shared BCD process (dashed numbered lines 1 to 5). 


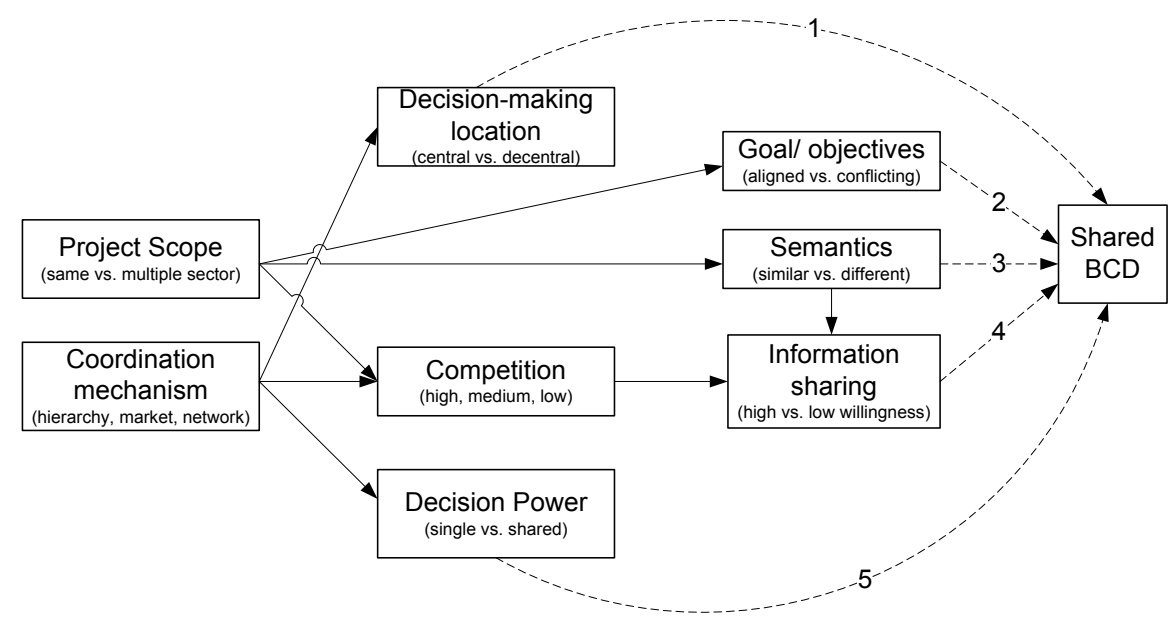

Fig. 3. Exploratory coordination - BCD framework

Decision-making location describes whether decisions in an inter-organizational network are made in centralized or decentralized manner. In the first case, only one $\mathrm{BC}$ is needed to evaluate an IT investment decision. In the case of decentralized decision-making, several BCs need to be prepared (Fig. 3. arrow 1), one for each decision-making unit. Decision-making also depends on the coordination structure, as e.g. in a network actors might need to develop, in addition to their own $\mathrm{BC}$, a shared $\mathrm{BC}$ with the other actors in the network. Such a joint model is based on input from each actor's individual BC.

As some actors might be competitors depending on the coordination structure), they might not want to reveal sensitive cost and benefit information to the other network partners. The competition between actors is expected to be higher when (i) the different actors are operating in the same sector or (ii) the inter-organizational relation is organized with a market structure.

The coordination structures are also found to influence the power dependency between the actors. Power dependency describes whether the decision power rests with a single actor or is shared among multiple actors. When multiple actors share the decision power they need to agree on the final BC (arrow 5).

However, this might not be that easy, as they might not only have different goals (and thus have difficulties to agree on a BC, arrow 2) but also might speak a different language (and, consequently, would not agree on the terms used in the $\mathrm{BC}$, arrow 3). This is especially true for actors from multiple sectors.

Information sharing is one of the most important aspects as it determines the willingness of actors to share their sensitive information, and their ability to actually put numbers in the BC (arrow 4). Information sharing is easier when actors speak the same language and is more difficult in case of competing actors. 


\section{Application of the Exploratory Framework in a Case Study}

Below we describe and analyze the case in our research determinants: coordination structure, project scope and coordination properties by following the order used in $\S 3$. We also explain the impact on the shared BCD by applying our exploratory framework to the case situation.

\subsection{Case Background (Coordination Structure and Project Scope)}

The coordination structure shown in Fig. 4 presents the relations between the actors in our case setting. Barges are used to transport containers from the port of Rotterdam to the hinterland and vice versa. Whenever a barge visits the port, it has to call on several terminals to load and unload containers. To guarantee short sojourn times in the port, the barge operator (BO) schedules convenient arrival times at the concerning terminals. The terminal operators (TO) on the other hand want to operate efficiently and have to decide when a barge can be processed, taking into account all kinds of restrictions, e.g. specific times at which containers need to be at the terminal.

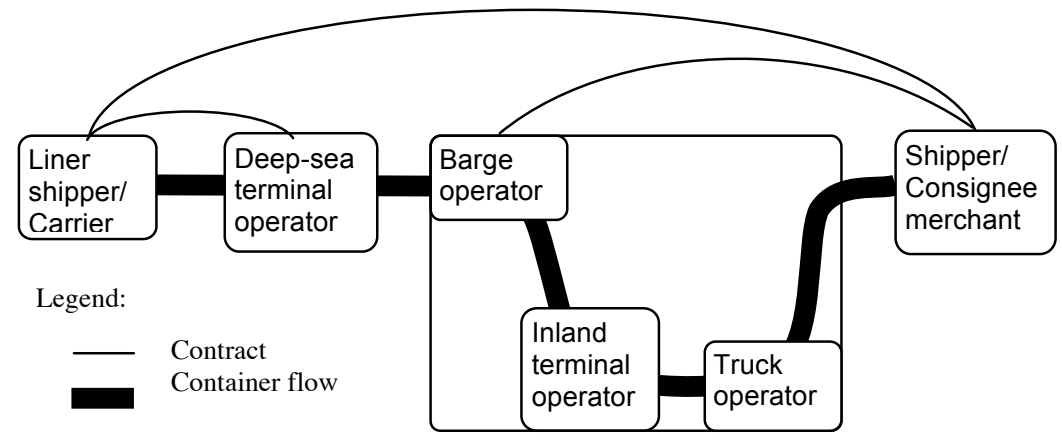

Fig. 4. Coordination structure of the case study setting

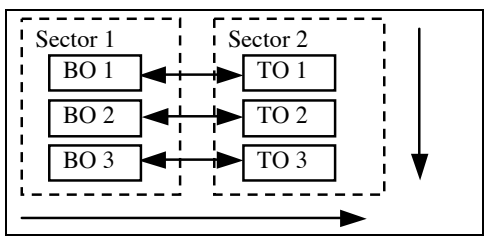

Fig. 5. Project scope case study

The Project scope, that we introduced in $\$ 3.3$, is described for the case at hand in Fig. 5. There one can see that the network involves both actors from the same sector, e.g. several BO's and several TO's, and actors from different sectors. These business characteristics complicate the project scope, e.g., parties want to stay autonomous, have no contractual relationships, and are reluctant to share information that possibly undermines their competitive position. 
Douma [24] shows that an integrated ES, enhanced by multi agent algorithms and controls, can support the alignment of barge rotations and terminal quay capacity, taking into account the business characteristics. We were involved in the BCD process to evaluate if an investment into such an integrated ES would be profitable.

\subsection{Impact of Coordination Properties on the Shared BC}

The application of BC guidelines developed earlier [25], turned out to be hardly possible as participating actors did not share sensitive cost and benefit information. To analyze the case study, we applied our conceptual framework introduced in $\$ 3.4$ to our case and show the results in Fig.6.

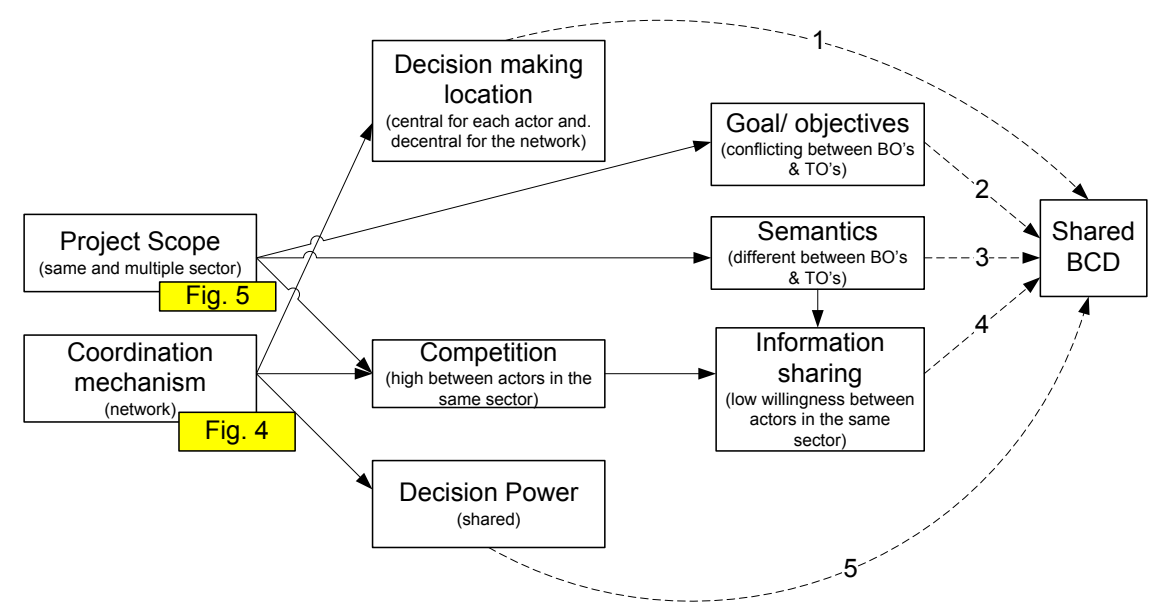

Fig. 6. Conceptual framework applied to the case study

Starting from the left, one can see that the harbor case involves several actors from both the same as well as different sectors, as it is illustrated in Fig. 5. The actors interact with each other in a network coordination structure, as it is shown in Fig. 4. Following from the network structure, the BCD process involved one individual BC for each actor (which was decided centrally by each actor) and a shared BC (Fig. 6. arrow 1). This was developed and decided on jointly by all actors in the network as they had shared decision power (arrow 5).

The proposition that actors from the same sector experience increased competition than actors from different sectors is supported by our case study where we observed high completion especially between the different BOs. This directly impacts the willingness to share sensitive cost and benefit information, which is needed for a shared BC (arrow 4). We found it particularly hard to quantify the expected benefits and costs mentioned vaguely by the different actors. However, without concrete numbers it is very difficult to arrive at a trusted $\mathrm{BC}$, no matter which guidelines one uses. The willingness to share information was further negatively impacted as actors from different sectors did not speak the same language and had different mental models (semantics). This rendered the discussions ineffective as actors had to spend 
much time on clarifying the meanings of the different terms used in the BC to describe the costs and benefits (arrow 3). E.g. actors had different understandings of what it means to achieve cost reduction or an improvement in planning.

Analyzing the goals of the actors from different sectors in our case study, we found that they were conflicting. The main goal of the BOs is to keep sojourn times short in the port and thus waiting times short at the terminal. However, the main goal of the TOs is to have long waiting lines in front of their terminals, so that they always have work for their employees to do. As Fig. 4 indicates, in the current situation, there is no contractual relationship between the BOs and TOs; so, no fines will be paid when barges arrive too late at the terminal or when terminals do not handle barges in the agreed upon time slot. This makes it very difficult to get agreement between BOs and TOs on how a solution could look like. It also makes the BCD very challenging as the actors did not agree on the costs and benefits (arrow 2). The TOs actually did not recognize the problem as urgent, as they currently achieve their goal of having long waiting lines, and therefore also had no incentives in investing into an improved planning system.

\section{Conclusion}

This paper reported on the first result in investigating the effects of project scope and coordination structure during the development of a shared BC for ES in interorganizational settings. Our contribution is an exploratory framework that explains how three coordination properties - competition, decision-making location and decision power, may help or impede the BCD process. This framework fills a gap in the current ES literature, which lacks comprehensive studies on BC decision-making in inter-organizational settings.

Our framework is a first proposal only. Our first application demonstrated that it made sense and was useful. To gain a deeper insight into the effects of coordination structure on the BCD process, we intend to use the framework as structure for further empirical investigations about shared BC in ES implementations.

The implications of our work are twofold: for practicing project managers, we think that if they are aware of these coordination aspects, they could devise strategies to mitigate their impact on the BCD process. For researchers, our framework could serve as an explanation vehicle that can be used in case study research. As we indicated earlier, we are interested in accumulating experiences which could evaluate the relationships between the concepts in our framework.

\section{References}

1. Kumar, K. and Hillegersberg van, J.: Enterprise Resource Planning: Introduction, Communications of the ACM, vol. 43, 22-26, (2000).

2. Bakos, J.: A strategic analysis of electronic marketplaces, MIS Quarterly, 295-310, (1991). 
3. Daneva, M. and Wieringa, R. J.: A Requirements Engineering Framework for Crossorganizational ERP systems, Requirements Engineering, vol. 11, 194-204, (2006).

4. Schubert, P. and William, S.: An Extended Framework for Comparing Expectations and Realized Benefits of Enterprise Systems Implementations, in Americas Conference on Information Systems (AMCIS), San Francisco, California, (2009).

5. Shang, S. and Seddon, P. B.: Assessing and Managing the Benefits of Enterprise Systems: the Business Manager's Perspective, Information Systems Journal, vol. 12, 271-299, (2002).

6. Ward, J. and Daniel, E.: Benefits Management: Delivering Value from IS\& IT Investments: John Wiley \& Sons, (2006).

7. Klein, R., Kupsch, F., and Scheer, A.: Modellierung interorganisationaler Prozesse mit Ereignisgesteuerten Prozessketten., Saarland University, Saarbruecken (2004).

8. Schulz, K. and Orlowska, M.: Facilitating cross-organisational workflows with a workflow view approach., Data \& Knowledge Engineering, vol. 51, 109-147, (2004).

9. Kishore, R., Zhang, H., and Rameshc, R.: Enterprise integration using the agent paradigm: foundations of multi-agent-based integrative business information systems, Decision Support Systems, vol. 42, 48-78, (2004).

10. Webster, J. and Watson, R. T.: Analyzing the Past to Prepare For the Future: Writing a Literature Review, MIS Quarterly, vol. 26, xiii-xxiii, (2002).

11. Ward, J., Daniel, E., and Peppard, J.: Building Better Business Cases for IT Investments, MIS Quarterly Executive, vol. 7, 1-15, (2008).

12. Crowston, K.: A coordination theory approach to organizational process design, Organization Science, vol. 8, 157 - 175, (1997).

13. Malone, T. W. and Crowston, K.: The interdisciplinary study of coordination, ACM Computing Surveys, vol. 26, 87 - 119, (1994).

14. Schmidt, M. J.: What's a Business Case? And Other Frequently Asked Questions, Solution Matrix (2003).

15. Gordijn, J.: Value-Based Requirements Engineering: Exploring Innovatie Ecommerce Ideas, Vrije Universiteit Amsterdam, Amsterdam, (2002).

16. Heide, J. B.: Interorganizational governance in marketing channels, The Journal of Marketing, vol. 58, 71-85, (1994).

17. Powel, W. W.: Neither market nor hierarchy: Network forms of organization, Research in Organizational Behavior, vol. 12, 295-336, (1990).

18. Ouchi, W. G.: Markets, Bureaucracies, and Clans, Administrative Science Quarterly, vol. 25, 129-141, (1980).

19. Jaffee, D.: Organization Theory: Tension and Change: McGraw-Hill, (2001).

20. Park, S. H.: Managing an Interorganizational Network: A Framework of the Institutional Mechanism for Network Control, Organization Studies, vol. 17, 795824, (1996).

21. Xu, L. and Beamon, B. M.: Supply chain coordination and cooperation mechanisms: an attribute-based approach., Journal of Supply Chain Management vol. 42, 4-12, (2006).

22. Thorelli, H. B.: Networks: Between Markets and Hierarchies, Strategic Management Journal, vol. 7, 37-51, Jan. - Feb., 1986 (1986).

23. Cook, K.: Exchange and power in networks of interorganizational relations, The Sociological Quarterly, 62-82, (1977).

24. Douma, A. M.: Aligning the Operations of Barges and Terminals through Distributed Planning, Universiteit Twente Enschede, (2008).

25. Eckartz, S., Daneva, M., Wieringa, R. J., and Hillegersberg van, J.: Crossorganizational ERP Management: How to Create a Successful Business Case, in 24th 
Annual ACM Symposium on Applied Computing, SAC'2009, Honolulu, Hawaii, USA, (2009). 